\title{
Poster Display as an Alternative Evaluation Method to Biochemistry Teaching
}

\author{
Silas P. Rodrigues and Patricia M.B. Fenandes*
}

Dept. de Ciências Fisiológicas, CBM, UFES, Vitória, ES.* E-mail: pat@npd.ufes.br

Biochemistry is present in different professional under gradation courses in which it seeks to attend several objectives. The discipline offered to the students of Biology Science Course at UFES is traditionally organized in a series of lectures to the basic information, a laboratory class related to each topic and a three written tests. Our students, as many from other courses, study biochemistry just because they have to. The teacher can alter the student behavior by changing the way in which they examine them. This work describes and analyses the experience of using poster display as an assessment and includes feedback from the students and teachers. At the beginning of the term the activity is explained to the class and groups are formed. They are oriented to search a full research paper, with "metabolism" as a key word. During the students' presentation, teachers and graduation students evaluate the production of a self-explanatory poster, assurance in the chosen work and involvement of all components of the group. A multiple-choice questionnaire was applied to 15-30 students from the five classes that had already done the activity. The teachers and the graduation students also had their opinions heard. $62.3 \%$ of the students agreed that the activity accomplishes its objective to stimulate the integration of general knowledge and comprehension of a specific scientific work, while it promotes the practice of presentation at seminars. $62.2 \%$ believed that it allows the learner to show its knowledge in a better way and $51 \%$ of the students were very much motivated within the activity. For $91.2 \%$ of the students, they should choose the article, as it allows a better correlation between biochemistry and personal affinities (42.7\%). Also, $98 \%$ believed that the activity should be carried out in groups, because it allows a deeper discussion (53.6\%), stimulate group activities (20\%) or permits the materials costs division $(22 \%)$. Only $1.8 \%$ of the learners thought that the traditional tests should be maintained, while the poster activity was suggested by $25 \%$ of them to be used in other subjects. At all, students and teachers agreed that the poster activity represents an interesting teaching tool to evaluate biochemistry students. 